\title{
Unilateral upper cervical posterior spinal artery syndrome following sneezing
}

\author{
N J Gutowski, R P Murphy, D J Beale
}

\begin{abstract}
A 35 year old man experienced severe transitory neck pain following a violent sneeze. This was followed by neurological symptoms and signs indicating a left sided upper cervical cord lesion. MRI showed an infarct at this site in the territory of the left posterior spinal artery. This discrete infarct was probably due to partial left vertebral artery dissection secondary to sneezing.
\end{abstract}

$(\Im$ Neurol Neurosurg Psychiatry 1992;55:841-843)

Infarction in the area supplied by the posterior spinal artery is rarely recognised clinically. We report a discrete upper cervical posterior spinal artery syndrome following a violent sneeze.

\section{Case report}

After a violent sneeze, a previously healthy 35 year old man had severe left sided neck pain lasting 10 minutes. An hour later he developed a left hemiparesis and hemisensory loss over 30 minutes. These symptoms persisted. The next day paraesthesiae ascended from the right foot to the mid-trunk over half an hour and he also developed urinary retention. There was no diplopia or dysphagia. He had not smoked for seven years.

On examination he was initially hypertensive at $160 / 120 \mathrm{mmHg}$, but after 12 hours this settled to $120 / 80 \mathrm{mmHg}$. He had a left Horner's syndrome with ipsilateral, trapezius weakness, reduced facial sensation to pain and temperature, $\mathrm{C} 2$ anaesthesia, posterior column loss and hemiparesis. There was right sided spinothalamic loss below T4. At presentation he had a flaccid left sided weakness with a global reduction in power to $1 / 5$ in the arm and $2 / 5$ in the leg and reduced reflexes. After 5 days there was left sided increased tone, pyramidal weakness with $2 / 5$ power in the arm and $3 / 5$ in the leg, brisk reflexes and an extensor plantar response.

Normal investigations included CT head scan, full myelogram and CSF examination. A full vascular screen was normal except vertebral dopplers which showed slower flow on the left side. The MRI 7 days after admission revealed the presence of abnormal increased signal from $\mathrm{C} 1$ to $\mathrm{C} 3$ on the left side of the cord on $\mathrm{T} 2$ and proton density weighted images. Axial T1 images before contrast showed no evidence of increased signal or cord expansion. After intravenous Gadolinium DTPA there was peripheral enhancement corresponding to the area of increased signal in keeping with acute infarction (fig 1). The left vertebral artery at this level was considerably smaller than the right. No intracranial abnormality was seen. There was no evidence of hind-brain herniation, or of a cervical syrinx. Vertebral angiography was not felt to be clinically justified.

\section{Neurology}

Department, North Staffordshire Royal Infirmary, Princes Road, Hartshill, Stoke-on-Trent, ST4 7LN, UK N J Gutowsk R P Murphy

X-Ray Department, Walsgrave Hospital, Walsgrave, Coventry, UK

D J Beale

Correspondence to: Dr Gutowski, Ludwig Institute for Cancer Research, (Middlesex Hospital/University College Branch), Courtauld Building, 91 Riding House Street, London W1P 8BT, UK

Received 6 August 1991 and in revised form 2 December 1991. Accepted 9 December 1991
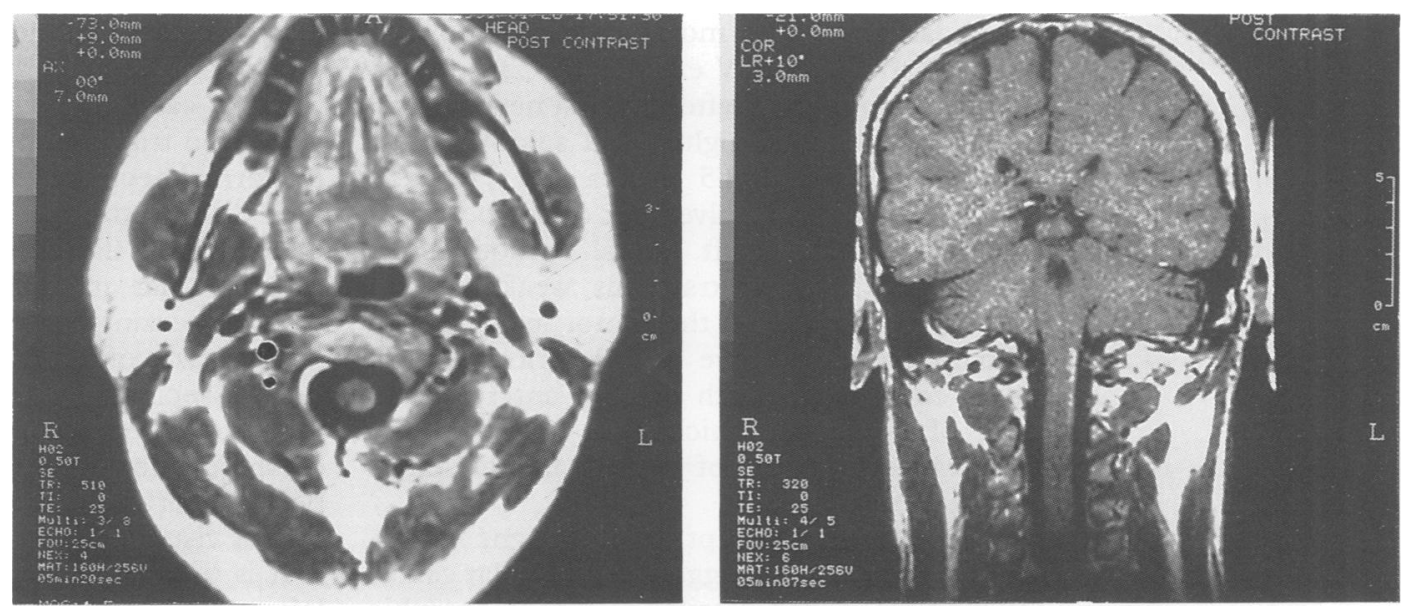

Figure 1 MR Scan (0.5T) seven days after admission. Axial T1 weighted SE 510/25 image after intravenous gadolinium contrast showing peripheral enhancement in the left postero-lateral aspect of the cord at C2 (left). Coronal T1 weighted post-contrast SE 320/25 image showing enhancement on the left lateral aspect of the cord between $C 1$ and C3 (right). 


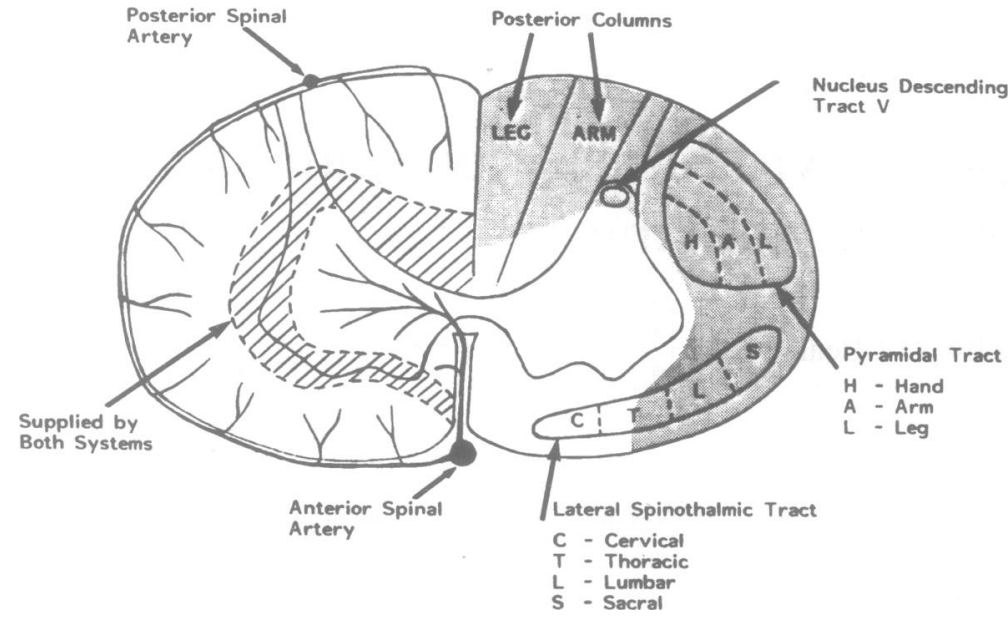

Figure 2 Cervical cord cross-section at C2. On the left showing the areas supplied by the peripheral and central arterial systems. On the right showing the main tracts, and the grey tone area indicating the projected lesion in the present case. overlapping but discrete (fig 2). The former was supplied entirely by the anterior spinal artery and the latter received supplies from both the anterior and posterior spinal arteries via the pial plexus.

The lesion predicted anatomically corresponded both to the area supplied by the left posterior spinal artery, ${ }^{2}$ that is, the left posterolateral rim of the cord (fig 2), and to the area of infarction seen on MRI (fig 1). Firstly, this demonstrates that cord infarction can be visualised by MRI when myelography is normal. Secondly, that the lesion causing the neurological signs was an infarct in the region supplied by the left posterior spinal artery at the level of $\mathrm{C} 1-3$.

Posterior spinal artery syndrome is rarely recognised clinically though there are a few clinico-pathological reports of mainly bilateral cases. ${ }^{34}$ The cardinal feature is posterior column involvement. In the presence of damage to the posterior horns there is suspended global anaesthesia. This posterior spinal artery syndrome cannot occur in a pure form since the posterior spinal arteries do not supply an area with clear cut boundaries and the pyramidal and antero-lateral tracts are often involved. ${ }^{5}$ The cause of posterior spinal artery occlusion is rarely ascertained. In early cases syphilitic arteritis was suspected. In single cases indirect trauma, atheromatous embolisation and intrathecal phenol have been the cause. $^{3}$ Considerable neurological improvement can occur after infarction, as in the present case, if the patient survives the initial period of swelling and oedema.

It is probable that this unusual left posterior spinal artery syndrome was due to partial left vertebral artery dissection secondary to sneezing. Vertebral artery dissection would have occluded a posterior radicular artery arising from it at the upper cervical level, in turn infarcting the area supplied by the posterior spinal artery. ${ }^{2} \mathrm{MRI}$ showed the left vertebral artery to be smaller than the right, and although this may be a normal variant it was felt to be compatible with a dissection, though the definitive investigation of angiography was not thought to be clinically justified. As our patient started to improve before a definitive diagnosis was made, he was treated with aspirin and was not anticoagulated.

Most cases of vertebral artery dissection have been triggered by cervical manipulation. ${ }^{6}$ Abnormal neck movements during other activities $^{7-10}$ including nose blowing, ${ }^{11}$ can cause dissection of the cervicocerebral arteries. We propose that in this case, neck movement during sneezing caused vertebral dissection.

Two cases of left upper cervical cord infarction associated with left sided medullary infarction, secondary to left vertebral artery dissection documented on angiography, have been reported. ${ }^{78}$ In neither case was the infarct visualised.

It is unlikely that the cause of this unusual left posterior spinal artery syndrome was a fibrocartilaginous embolus to the spinal arteries for the following reasons. In fibrocartilaginous embolism most of the emboli are found 
in vessels in the anterior part of the subarachnoid space, usually in the distribution of the anterior spinal artery. ${ }^{12}{ }^{13}$ Also, the spinal cord infarct is typically central, with greater involvement of the anterior and lateral horns and columns.

We believe this is the first case of isolated unilateral upper cervical posterior spinal artery syndrome demonstrated on MRI.

1 Schneider RC, Crosby EC. Vascular insufficiency of brain stem and spinal cord in spinal trauma. Neurology 1959;9:643-56.

2 Turnbull IM, Brieg A, Hassler O. Blood supply of cervical spinal cord in man. $\mathcal{F}$ Neurosurg 1966;24:951-65.

3 Hughes JT. Thrombosis of the posterior spinal arteries. Neurology 1970;20:659-64.

4 Hegedus K, Fekete I. Case report of infarction in the region of the posterior spinal arteries. Eur Arch Psychiatr Neurol of the posterior spinal
5 Lazorthes G. Pathology, classification and clinical aspects of vascular diseases of the spinal cord. In: Vinken PJ, Bruyn GW, eds. Handbook of clinical neurology. Oxford: NorthHolland, 1972;12:492-506.

6 Sherman DG, Hart RG, Easton JD. Abrupt change in head position and cerebral infarction. Stroke 1981;12:2-6.

7 Alom J, Matias-Guiu J, Padró L. Molins M, Romero F, Codina A. Spontaneous dissection of intracranial vertebral artery: clinical recovery with conservative treatment. bral artery: clinical recovery with conservative tre

f Neurol Neurosurg Psychiatry 1986;49:599-600.
8 Pryse-Phillips W. Infarction of the medulla and cervical cord ryse-Phillips $W$. Infarction of the medulla and

9 Young CA, Chadwick DW, Humphrey PRD. Extracranial vertebral artery dissection following tonic clonic seizure. $\mathcal{f}$ Neurol Neurosurg Psychiatry 1991;54:365-6.

10 Hart RG, Easton JD. Dissections of cervical and cerebral arteries. In: Barnett HJM, ed. Neurologic Clinics, Symposium on Cerebral Vascular Disease. Philadelphia: $W B$ Saunders, 1983;1:155-82.

11 Roome NS, Aberfeld DC. Spontaneous dissecting aneurysm of the internal carotid artery. Arch Neurol 1977;34: 251-2

12 Bots G Th AM, Wattendorff AR, Buruma OJS, Roos RAC, Endtz LJ. Acute myelopathy caused by fibrocartilaginous emboli. Neurology 1981;31:1250-6.

13 Case Records of the Massachusetts General Hospital (Case 5-1991). N Engl f Med 1991;324:322-32. 